\title{
Clinical Significance of Lymph Node Ratio and Location of Nodal Involvement in Patients with Right Colon Cancer
}

\author{
Hirotoshi Kobayashi Masayuki Enomoto Tetsuro Higuchi Hiroyuki Uetake \\ Satoru lida Toshiaki Ishikawa Megumi Ishiguro Shunsuke Kato \\ Kenichi Sugihara \\ Department of Surgical Oncology, Graduate School, Tokyo Medical and Dental University, Tokyo, Japan
}

\section{Key Words}

Colorectal carcinoma $\cdot$ Lymph node metastasis •

Lymph node ratio $\cdot$ Complete mesocolic excision

\begin{abstract}
Background/Aims: Increasing negative lymph node count has been reported to be associated with better outcomes in patients with colon cancer. The present study aimed to clarify the clinical significance of the lymph node ratio (LNR) and location of lymph node metastasis (LNM) in patients with stage III right colon cancer. Methods: We enrolled 820 patients who had undergone curative resection due to colon cancer at a single institution between 1991 and 2005. Among them, 197 underwent curative resection for T2-T4 right colon cancer. We evaluated the oncological outcomes according to LNR (quartiles) and distribution of LNM ( $\mathrm{n} 1=\mathrm{LNM}$ adjacent to the colon or along the vascular arcades of the marginal arteries; $\mathrm{n} 2$ = LNM along the major vessels; n3 = LNM near the roots of the major vessels). Results: The rates of LNM in T2, T3 and T4 right colon cancer were 11.1, 38.6 and 58.0\%, respectively ( $p<0.0001$ ). Recurrence rates were $27.3,37.5$ and $57.1 \%$ in patients with $\mathrm{n} 1, \mathrm{n} 2$ and $\mathrm{n} 3 \mathrm{LNM}$, respectively
\end{abstract}

$(p<0.0001)$. LNR $(p<0.0001)$ and distribution of LNM ( $p=$ 0.046) were independent risk factors for recurrence in patients with stage III right colon cancer. Conclusions: Some patients with extensive LNM benefited from lymph node dissection with high ligation. Those with T3-T4 right colon cancer are suitable candidates for lymph node dissection with high ligation. Adding the concept of LNR and location of LNM to conventional TNM staging could improve the accuracy of evaluating nodal status.

Copyright $\odot 2011$ S. Karger AG, Basel

\section{Introduction}

Colorectal cancer is the second most common cause of cancer death in the USA and Japan, and the occurrence of this disease is rapidly increasing in Japan $[1,2]$. Although there has been remarkable progress in chemotherapy for colorectal cancer, the standard therapy for resectable colorectal cancer is still curative resection with lymph node dissection. The introduction of total mesorectal excision led to a decrease in the local recurrence of rectal cancer and improved survival [3-5]. Complete me-

\section{KARGER}

Fax +41613061234 E-Mail karger@karger.ch www.karger.com (c) 2011 S. Karger AG, Basel

0253-4886/11/0283-0190\$38.00/0

Accessible online at:

www.karger.com/dsu
Hirotoshi Kobayashi, MD, Assistant Professor

Department of Surgical Oncology, Division of Colorectal Surgery

Tokyo Medical and Dental University

1-5-45 Yushima, Bunkyo-ku, Tokyo 113-8519 (Japan)

Tel. +81 35803 5261, E-Mail h-kobayashi.srg2@tmd.ac.jp 
socolic excision (CME) for colon cancer has recently been proposed as well as total mesorectal excision for rectal cancer [6]. Mesocolic excision with high ligation of the main feeding artery has been a standard technique for advanced colon cancer in Japan $[7,8]$. However, high ligation of the supplying arteries and the draining veins for right colon cancer is sometimes complicated because of variations in vascular branches $[9,10]$. The precise indication for CME in patients with stage III right colon cancer has not been clarified.

Recent studies have reported that the concept of the lymph node ratio (LNR), which is the proportion of metastatic to examined lymph nodes, is a prognostic factor in patients with stage III colorectal cancer [11-16]. On the other hand, it has been reported that the distribution of lymph node metastasis (LNM) is a prognostic factor in patients with stage III colon cancer [7]. However, LNR and the location of LNM have not been investigated simultaneously as prognostic factors in patients with stage III colon cancer.

The present study aimed to clarify the value of lymph node dissection with high ligation of the primary feeding artery for right colon cancer. We also evaluated the clinical significance of the LNR and the distribution of LNM in patients with stage III right colon cancer.

\section{Patients and Methods}

\section{Patients}

We reviewed the medical charts of 820 patients who underwent curative surgery for colon carcinoma at a single institution (the Department of Surgical Oncology, Tokyo Medical and Dental University, Tokyo, Japan) between January 1991 and December 2005. Among them, 197 underwent curative resection with high ligation of the main feeding arteries and CME for T2-T4 right colon cancer. The standard practice of nodal dissection for advanced colon cancer at our institution involves ligating the major artery to the region of resection at its origin. Resection of the right colon involves resection of the ileocolic artery and right colonic artery at their origin from the superior mesenteric artery. We usually ligate only the right branch of the middle colic artery, although the lymph nodes around the root of the middle colic artery are dissected. The resected specimen with the mesentery was stretched and pinned to a cork board. The surgeon identified the lymph nodes, isolated them and recorded both their number and distribution. In this study, the surgeons harvested the lymph nodes from the specimen to evaluate the precise location of nodal metastases; we acknowledge that this technique is not the custom in the vast majority of centers in North America or Europe. After formalin fixation, the specimens and lymph nodes were examined by the pathologist. Patients with familial adenomatous polyposis, kindred with cancer family syndrome or ulcerative colitis were excluded from this study. We evaluated the oncological outcomes according to the distribution of LNM.

Vascular High Ligation for Right Colon Cancer
Location of LNM

The distribution of LNM was classified as n0 (no LNM), n1 (LNM adjacent to the colon or along the vascular arcades of the marginal arteries), n2 (LNM along the major vessels) or n3 (LNM near the roots of the major vessels).

\section{Lymph Node Ratio}

We calculated the LNR as the proportion of metastatic to examined lymph nodes and then classified the LNRs into subgroups according to the following quartiles: $>0$ to $<0.07, \geq 0.07$ to $<0.15$, $\geq 0.15$ to $<0.30$ and $\geq 0.30$.

\section{Follow-Up Program}

All patients were strictly followed up. During the first 3 years, patients were followed up every 3 months with clinical assessment and measurement of serum carcinoembryonic antigen, and every 6 months with chest X-rays and abdominal ultrasonography or computed tomography. For the next 2 years, all tests were performed every 6 months. Colonoscopy was performed 1 year after surgery and every 2 years for the next 4 years.

\section{Statistical Analysis}

Data were statistically analyzed using JMP 8 (SAS Institute Inc., Cary, N.C., USA). All data are expressed as means \pm standard deviation. Data concerning age and number of lymph nodes were analyzed using the Mann-Whitney U test and Kruskal-Wallis test for 2 and 3 or more groups, respectively. Associations between each parameter and LNM or recurrence were analyzed using the $\chi^{2}$ test. Independent risk factors for LNM and recurrence were determined using logistic regression analysis after forward stepwise selection. The actuarial survival of patients was calculated using the Kaplan-Meier method. Overall survival rates in all groups were compared using the log-rank test. Cox's proportional hazard regression analysis was applied to determine which factors independently affected postoperative survival. Forward selection was adopted in a stepwise regression procedure. Statistical significance was established at $\mathrm{p}<0.05$ for all results.

\section{Results}

\section{Patient Characteristics}

The characteristics of the patients, most of whom had lymphovascular invasion, are listed in table 1 . The numbers of patients with stage I (T2), II and III cancers were 24,91 and 82 , respectively.

\section{Lymph Node Metastasis}

The mean number of lymph nodes harvested from 82 of the 197 patients was $20 \pm 12$. The median number of positive nodes was 3 (range 1-23). The rates of LNM in patients with T2, T3 and T4 right colon cancer were 11.1, 38.6 and $58.0 \%$, respectively. The numbers of patients with n1, n2 and n3 LNM were 44 (53.6\%), 24 (29.3\%) and 14 (17.1\%), respectively. The numbers of patients with TNM N1 and N2 were 54 (65.9\%) and 28 (34.1\%), respec- 
Table 1. Risk factors for LNM

\begin{tabular}{|c|c|c|c|c|c|c|c|}
\hline & & \multicolumn{3}{|c|}{ Univariate analysis } & \multicolumn{3}{|c|}{ Multivariate analysis } \\
\hline & & LNM (-) & $\operatorname{LNM}(+)$ & $\mathrm{p}$ value & odds ratio & $95 \% \mathrm{CI}$ & $\mathrm{p}$ value \\
\hline \multirow[t]{2}{*}{ Gender } & male & $61(61)$ & $39(39)$ & & & & \\
\hline & female & $54(56)$ & $43(44)$ & 0.45 & & & \\
\hline \multirow{3}{*}{$\begin{array}{l}\text { Location of } \\
\text { colon cancer }\end{array}$} & ascending colon & $60(62)$ & $37(38)$ & & & & \\
\hline & cecum & $34(52)$ & $31(48)$ & & & & \\
\hline & transverse colon & $21(60)$ & $14(40)$ & 0.47 & & & \\
\hline \multirow{3}{*}{$\begin{array}{l}\text { Depth of } \\
\text { tumor invasion }\end{array}$} & $\mathrm{T} 2$ & $24(89)$ & $3(11)$ & & 1 & & \\
\hline & T3 & $62(61)$ & $39(39)$ & & 3.1 & $0.79-12.1$ & 0.10 \\
\hline & $\mathrm{T} 4$ & $29(42)$ & $40(58)$ & 0.0001 & 5.4 & $1.36-21.9$ & 0.017 \\
\hline \multirow{3}{*}{$\begin{array}{l}\text { Histological } \\
\text { type }\end{array}$} & well-differentiated adenocarcinoma & $63(68)$ & $29(32)$ & & 1 & & \\
\hline & other & $50(49)$ & $53(51)$ & 0.0049 & 1.8 & $0.91-3.40$ & 0.093 \\
\hline & unknown & 2 & 0 & & & & \\
\hline \multirow{2}{*}{$\begin{array}{l}\text { Lymphatic } \\
\text { invasion }\end{array}$} & absent & $36(97)$ & $1(3)$ & & 1 & & \\
\hline & present & $79(49)$ & $9(51)$ & $<0.0001$ & 25.0 & $3.25-200$ & 0.0020 \\
\hline \multirow{2}{*}{$\begin{array}{l}\text { Venous } \\
\text { invasion }\end{array}$} & absent & $17(89)$ & $2(11)$ & & 1 & & \\
\hline & present & $98(55)$ & $80(45)$ & 0.0038 & 2.7 & $0.50-14.3$ & 0.25 \\
\hline
\end{tabular}

Values represent numbers of patients (percentage), unless indicated otherwise. $\mathrm{CI}=\mathrm{Confidence} \mathrm{interval}$.

Table 2. Association between clinicopathological features and LNR and distribution of LNM

\begin{tabular}{|c|c|c|c|c|c|c|c|c|c|c|}
\hline & & \multicolumn{5}{|l|}{ LNR } & \multicolumn{4}{|c|}{ Distribution of LNM } \\
\hline & & $\begin{array}{l}>0 \text { to } \\
<0.07\end{array}$ & $\begin{array}{l}\geq 0.07 \text { to } \\
<0.15\end{array}$ & $\begin{array}{l}\geq 0.15 \text { to } \\
<0.30\end{array}$ & $\geq 0.30$ & $\begin{array}{l}\mathrm{p} \\
\text { value }\end{array}$ & $\mathrm{n} 1$ & $\mathrm{n} 2$ & n3 & $\begin{array}{l}\mathrm{p} \\
\text { value }\end{array}$ \\
\hline \multicolumn{2}{|c|}{ Number of lymph nodes retrieved } & $30 \pm 11$ & $21 \pm 9$ & $18 \pm 7$ & $16 \pm 8$ & $<0.0001$ & $23 \pm 11$ & $18 \pm 6$ & $23 \pm 11$ & 0.16 \\
\hline \multicolumn{2}{|c|}{ Number of positive nodes } & $1 \pm 0.4$ & $2 \pm 1$ & $4 \pm 1$ & $7 \pm 5$ & $<0.0001$ & $3 \pm 2$ & $4 \pm 3$ & $6 \pm 6$ & 0.10 \\
\hline \multirow[t]{2}{*}{ Gender } & male & $6(15)$ & $13(33)$ & $10(26)$ & $10(26)$ & & $22(56)$ & $9(23)$ & $8(21)$ & \\
\hline & female & $14(33)$ & $9(21)$ & $12(28)$ & $8(19)$ & 0.25 & $22(51)$ & $15(35)$ & $6(14)$ & 0.45 \\
\hline \multirow{3}{*}{$\begin{array}{l}\text { Location of } \\
\text { colon cancer }\end{array}$} & ascending colon & $8(22)$ & $11(30)$ & $12(32)$ & $6(16)$ & & $21(57)$ & $10(27)$ & $6(16)$ & \\
\hline & cecum & $7(23)$ & $10(32)$ & $8(26)$ & $6(19)$ & & $17(55)$ & $11(35)$ & $3(10)$ & \\
\hline & transverse colon & $5(36)$ & $1(7)$ & $2(14)$ & $6(43)$ & 0.23 & $6(43)$ & $3(21)$ & $5(36)$ & 0.29 \\
\hline \multirow{3}{*}{$\begin{array}{l}\text { Depth of } \\
\text { tumor invasion }\end{array}$} & $\mathrm{T} 2$ & $1(33)$ & 0 & $2(67)$ & 0 & & $3(100)$ & 0 & 0 & \\
\hline & $\mathrm{T} 3$ & $11(28)$ & $17(44)$ & $7(18)$ & $4(10)$ & & $20(51)$ & $9(23)$ & $10(26)$ & \\
\hline & $\mathrm{T} 4$ & $8(20)$ & $5(13)$ & $13(33)$ & $14(35)$ & 0.0058 & $21(53)$ & $15(38)$ & $4(10)$ & 0.14 \\
\hline \multirow[t]{2}{*}{ Histological type } & $\begin{array}{l}\text { well-differentiated } \\
\text { adenocarcinoma }\end{array}$ & $9(31)$ & $11(38)$ & $6(21)$ & $3(10)$ & & $14(48)$ & $10(34)$ & $5(17)$ & \\
\hline & other & $11(21)$ & $11(21)$ & $16(30)$ & $15(28)$ & 0.10 & $30(57)$ & $14(26)$ & $9(17)$ & 0.72 \\
\hline \multirow{2}{*}{$\begin{array}{l}\text { Lymphatic } \\
\text { invasion }\end{array}$} & absent & 0 & $1(100)$ & 0 & 0 & & 0 & 0 & $1(100)$ & \\
\hline & present & $20(25)$ & $21(26)$ & $22(27)$ & $18(22)$ & 0.43 & $44(54)$ & $24(30)$ & $13(16)$ & 0.086 \\
\hline \multirow[t]{2}{*}{ Venous invasion } & absent & 0 & 0 & $2(100)$ & 0 & & $1(50)$ & $1(50)$ & 0 & \\
\hline & present & $20(25)$ & $22(28)$ & $20(25)$ & $18(23)$ & 0.13 & $43(54)$ & $23(29)$ & $14(18)$ & 0.72 \\
\hline
\end{tabular}

Values represent numbers of patients (percentage), unless indicated otherwise. 
Table 3. Risk factors for recurrence

\begin{tabular}{|c|c|c|c|c|c|c|c|}
\hline & & \multicolumn{3}{|c|}{ Univariate analysis } & \multicolumn{3}{|c|}{$\begin{array}{l}\text { Multivariate analysis } \\
\text { after stepwise regression }\end{array}$} \\
\hline & & recurrence $(-)$ & recurrence $(+)$ & $\mathrm{p}$ value & odds ratio & $95 \% \mathrm{CI}$ & $\mathrm{p}$ value \\
\hline \multirow[t]{2}{*}{ Gender } & male & $80(80)$ & $20(20)$ & & & & \\
\hline & female & $81(84)$ & $16(16)$ & 0.52 & & & \\
\hline \multirow{3}{*}{$\begin{array}{l}\text { Location of } \\
\text { colon cancer }\end{array}$} & ascending colon & $83(86)$ & $14(14)$ & & & & \\
\hline & cecum & $51(78)$ & $14(22)$ & & & & \\
\hline & transverse colon & $27(77)$ & $8(23)$ & 0.38 & & & \\
\hline \multirow{3}{*}{$\begin{array}{l}\text { Depth of } \\
\text { tumor invasion }\end{array}$} & $\mathrm{T} 2$ & $26(96)$ & $1(4)$ & & 1 & & \\
\hline & T3 & $87(86)$ & $14(14)$ & & & & \\
\hline & $\mathrm{T} 4$ & $48(70)$ & $21(30)$ & 0.0025 & 2.03 & $0.82-5.05$ & 0.13 \\
\hline \multirow{3}{*}{$\begin{array}{l}\text { Histological } \\
\text { type }\end{array}$} & well-differentiated adenocarcinoma & $80(87)$ & $12(13)$ & & & & \\
\hline & other & $79(77)$ & $24(23)$ & 0.065 & & & \\
\hline & unknown & 2 & 0 & & & & \\
\hline \multirow{2}{*}{$\begin{array}{l}\text { Lymphatic } \\
\text { invasion }\end{array}$} & absent & $36(97)$ & $1(3)$ & & & & \\
\hline & present & $125(78)$ & $35(22)$ & 0.0065 & & & \\
\hline \multirow{2}{*}{$\begin{array}{l}\text { Venous } \\
\text { invasion }\end{array}$} & absent & $19(100)$ & 0 & & 1 & & \\
\hline & present & $142(80)$ & $36(20)$ & 0.030 & 4792738 & $4.8 \times 10^{9}-$ & 0.022 \\
\hline \multirow{3}{*}{$\begin{array}{l}\text { Number } \\
\text { of LNM }\end{array}$} & No & $108(94)$ & $7(6)$ & & & & \\
\hline & N1 & $40(74)$ & $14(26)$ & & & & \\
\hline & N2 & $13(46)$ & $15(54)$ & $<0.0001$ & & & \\
\hline \multirow{4}{*}{$\begin{array}{l}\text { Location } \\
\text { of LNM }\end{array}$} & n0 & $108(94)$ & $7(6)$ & & 1 & & \\
\hline & $\mathrm{n} 1$ & $32(74)$ & $12(26)$ & & & & \\
\hline & $\mathrm{n} 2$ & $15(63)$ & $9(38)$ & & & & \\
\hline & $\mathrm{n} 3$ & $6(43)$ & $8(57)$ & $<0.0001$ & 3.91 & $1.03-14.93$ & 0.046 \\
\hline \multirow[t]{4}{*}{ LNR } & 0 & $108(94)$ & $7(6)$ & & 1 & & \\
\hline & $<0.15$ & $34(81)$ & $8(19)$ & & & & \\
\hline & $\geq 0.15$ to $<0.30$ & $12(55)$ & $10(45)$ & & 6.45 & $2.56-16.13$ & $<0.0001$ \\
\hline & $\geq 0.30$ & $7(39)$ & $11(61)$ & 0.0099 & & & \\
\hline
\end{tabular}

Values represent numbers of patients (percentage), unless indicated otherwise. $\mathrm{CI}=\mathrm{Confidence} \mathrm{interval}$.

tively. Among the various parameters studied, depth of tumor invasion ( $\mathrm{p}=0.0001)$, histological type $(\mathrm{p}=0.0049)$, lymphatic invasion $(\mathrm{p}<0.0001)$ and venous invasion $(\mathrm{p}=$ 0.0038 ) were risk factors for LNM in the univariate analysis (table 1). Multivariate analysis revealed that the depth of tumor invasion (T4; $\mathrm{p}=0.017)$ and lymphatic invasion $(\mathrm{p}=0.0020)$ were independent risk factors. None of the patients with T2 right colon cancer had n2 or n3 LNM (table 2). The distribution of LNM was not associated with any clinicopathological parameters (table 2).

\section{Lymph Node Ratio}

The LNR was associated with the depth of tumor invasion $(\mathrm{p}=0.0058)$ and the number of positive lymph nodes
( $\mathrm{p}<0.0001$; table 2). There was a negative correlation between the number of retrieved lymph nodes and the LNR $(\mathrm{p}<0.0001)$.

\section{Recurrence}

Among 197 patients, 36 (18.3\%) developed recurrence over a median follow-up period of 4.1 years. Recurrence rates were $6.1,27.3,37.5$ and $57.1 \%$ in patients with $\mathrm{n} 0, \mathrm{n} 1$, $\mathrm{n} 2$ and $\mathrm{n} 3 \mathrm{LNM}$, respectively ( $\mathrm{p}<0.0001)$. We found 3 locoregional recurrences in the present study (3/197, 1.5\%). The locoregional recurrence rates in T2, T3 and T4 tumors were $0 \%(0 / 27), 0.99 \%(1 / 101)$ and $2.9 \%(2 / 69)$, respectively. Two of the 3 patients with locoregional recurrence also had distant metastasis. The depth of tumor invasion $(\mathrm{p}=$ 

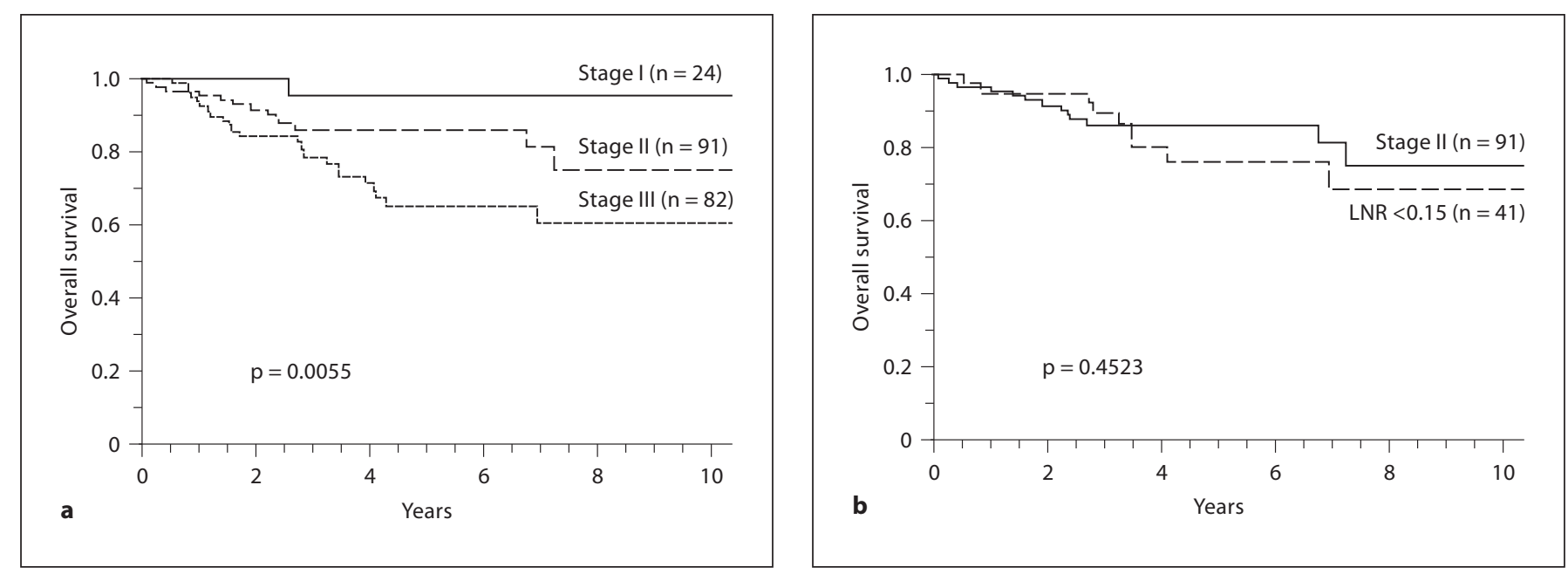

Fig. 1. a Overall survival curves according to the TNM stage. b Overall survival curves for patients with stage II cancer and stage III cancer $(\mathrm{LNR}<0.15)$.

$0.0025)$, lymphatic invasion $(\mathrm{p}=0.0065)$, venous invasion $(\mathrm{p}=0.030)$, number of LNM $(\mathrm{p}<0.0001)$, location of LNM $(\mathrm{p}<0.0001)$ and LNR $(\mathrm{p}=0.0099)$ were risk factors for recurrence in the univariate analysis. Among these, stepwise regression analysis selected depth of tumor invasion, venous invasion, location of LNM and LNR as risk factors for recurrence. Logistic regression analysis revealed that venous invasion $(\mathrm{p}=0.022)$, the location of LNM $(\mathrm{n} 0-\mathrm{n} 2 \mathrm{vs}$. $\mathrm{n} 3, \mathrm{p}=0.046)$ and LNR (0-0.14 vs. $0.15-1.0, \mathrm{p}<0.0001)$ were independent risk factors for recurrence (table 3 ).

\section{Survival}

The 5-year overall survival rates in patients with stages I $(\mathrm{n}=24)$, II $(\mathrm{n}=91)$ and III $(\mathrm{n}=82)$ right colon cancer were $95.2,86.3$ and $65.0 \%$, respectively ( $\mathrm{p}=0.0055$; fig $1 \mathrm{a})$. In terms of LNM distribution, the 5-year overall survival rates in patients with $\mathrm{n} 1, \mathrm{n} 2$ and $\mathrm{n} 3 \mathrm{LNM}$ were $76.4,60.0$ and $37.5 \%$, respectively $(p=0.0002)$. There was no difference in overall survival between patients with LNR $<0.15$ and those with stage II cancer ( $p=0.45$; fig. $1 b)$. Depth of tumor invasion $(\mathrm{p}=0.017)$ and lymphatic invasion $(\mathrm{p}=$ $0.025)$, number $(\mathrm{p}=0.0006)$ and distribution $(\mathrm{p}=0.0002)$ of LNM, and LNR $(\mathrm{p}<0.0001)$ were prognostic factors according to the log-rank test (table 4). Among these, stepwise regression analysis selected depth of tumor invasion and location of LNM as variables for further analysis. Depth of tumor invasion (T2 vs. T3-T4, p = 0.030) and location of LNM (n0-n1 vs. $n 2-n 3, p=0.0050)$ were independent risk factors in the Cox proportional hazards model.

\section{Discussion}

Lymph flow in colorectal cancer was described a century ago [17]. Today, the standard treatment for resectable colorectal cancer is radical resection accompanied by systematic lymph node dissection. However, the optimal extent of lymph node dissection remains controversial. Some studies have shown an advantage of high ligation in patients with colorectal cancer [18-20], whereas others could not demonstrate such an advantage [21-24]. High ligation of major vessels is a standard procedure for advanced colorectal cancer in Japan, although few reports have addressed indications for this technique.

Vessels of the right colon vary anatomically. GarciaRuiz et al. [9] reported that it was unusual for the right colic artery to arise directly from the superior mesenteric artery (10.7\%). Yamaguchi et al. [10] demonstrated variations in the anatomy of the veins of the right colon. Therefore, high ligation for right colon cancer is sometimes complicated, and thus indications for high ligation for right colon cancer should be clarified.

The present study demonstrated that among patients with LNM, $48.7 \%$ with T3 and $47.5 \%$ with T4 right colon cancer had more distant LNM than those with pericolic cancer. On the other hand, none of the patients with T2 right colon cancer had $\mathrm{n} 2$ or $\mathrm{n} 3 \mathrm{LNM}$. This study also showed that the depth of tumor invasion was an independent risk factor for LNM. The extent of lymph node dissection should be determined according to the depth of tumor invasion. A suitable candidate for CME with high 
Table 4. Prognostic factors in patients with T2-T4 right colon cancer

\begin{tabular}{|c|c|c|c|c|c|c|c|}
\hline & & \multicolumn{3}{|c|}{ Univariate analysis } & \multicolumn{3}{|c|}{$\begin{array}{l}\text { Cox hazard model } \\
\text { after stepwise regression }\end{array}$} \\
\hline & & number & $\%$ & $\mathrm{p}$ value & HR & $95 \%$ CI & $\mathrm{p}$ value \\
\hline \multirow[t]{2}{*}{ Gender } & male & 100 & 51 & & & & \\
\hline & female & 97 & 49 & 0.48 & & & \\
\hline \multirow{3}{*}{$\begin{array}{l}\text { Location of } \\
\text { colon cancer }\end{array}$} & ascending colon & 97 & 49 & & & & \\
\hline & cecum & 65 & 33 & & & & \\
\hline & transverse colon & 35 & 18 & 0.31 & & & \\
\hline \multirow{3}{*}{$\begin{array}{l}\text { Depth of } \\
\text { tumor invasion }\end{array}$} & $\mathrm{T} 2$ & 27 & 14 & & 1 & & \\
\hline & T3 & 101 & 51 & & 2.33 & $1.07-9.87$ & 0.030 \\
\hline & $\mathrm{T} 4$ & 69 & 35 & 0.017 & & & \\
\hline \multirow{3}{*}{$\begin{array}{l}\text { Histological } \\
\text { type }\end{array}$} & well-differentiated adenocarcinoma & 92 & 47 & & & & \\
\hline & other & 103 & 52 & 0.093 & & & \\
\hline & unknown & 2 & 1 & & & & \\
\hline \multirow{2}{*}{$\begin{array}{l}\text { Lymphatic } \\
\text { invasion }\end{array}$} & absent & 37 & 19 & & & & \\
\hline & present & 160 & 81 & 0.025 & & & \\
\hline \multirow{2}{*}{$\begin{array}{l}\text { Venous } \\
\text { invasion }\end{array}$} & absent & 19 & 10 & & & & \\
\hline & present & 178 & 90 & 0.13 & & & \\
\hline \multirow{3}{*}{$\begin{array}{l}\text { Number } \\
\text { of LNM }\end{array}$} & N0 & 115 & 58 & & & & \\
\hline & N1 & 54 & 27 & & & & \\
\hline & $\mathrm{N} 2$ & 28 & 14 & 0.0006 & & & \\
\hline \multirow{4}{*}{$\begin{array}{l}\text { Location } \\
\text { of LNM }\end{array}$} & no & 115 & 58 & & 1 & & \\
\hline & $\mathrm{n} 1$ & 44 & 22 & & & & \\
\hline & $\mathrm{n} 2$ & 24 & 12 & & 1.64 & $1.17-2.28$ & 0.0050 \\
\hline & $\mathrm{n} 3$ & 14 & 7 & 0.0002 & & & \\
\hline \multirow[t]{4}{*}{ LNR } & 0 & 115 & 58 & & & & \\
\hline & $<0.15$ & 42 & 21 & & & & \\
\hline & $\geq 0.15$ to $<0.30$ & 22 & 11 & & & & \\
\hline & $\geq 0.30$ & 18 & 9 & $<0.0001$ & & & \\
\hline
\end{tabular}

$\mathrm{HR}=$ Hazard ratio; $\mathrm{CI}=$ confidence interval.

ligation is a patient with T3-T4 right colon cancer, whereas high ligation might be unnecessary for T2 cancer.

Hohenberger et al. [6] recently described improved oncological outcomes after adopting CME for colon cancer. They reduced 5-year local recurrence rates from 6.5 to $3.6 \%$ and increased cancer-related 5-year survival rates from 82.1 to $89.1 \%$. All of our patients underwent CME with high ligation for right colon cancer. In the present study, the locoregional recurrence rates in T2, T3 and T4 tumors were $0,0.99$ and $2.9 \%$, respectively. The recurrence rates in patients with $\mathrm{n} 2$ and $\mathrm{n} 3 \mathrm{LNM}$ were 37.5 and $57.1 \%$, respectively. This means that $>40 \%$ of patients with LNM around the roots of major vessels did not de- velop recurrence after curative resection for right colon cancer, unless they had distant metastasis. Thus, CME with high ligation should be a standard treatment for advanced colon cancer, although the population of patients with n3 LNM who do not have distant metastasis may be small.

CME is not new [25], and surgical techniques have been applied in embryological tissue planes for colon cancer resection. However, this technique differs according to the surgeon. In fact, West et al. [26] reported that specimens resected at two different hospitals differed in terms of the area of the mesentery and the distance between the tumor and the high vascular tie. 
The present study investigated the usefulness of the number and distribution of LNM, and LNR as prognostic markers for colon cancer. The location of LNM was an independent risk factor for both recurrence and survival. We used stepwise regression analysis due to the limited sample size. The number of LNM was excluded from further analysis of recurrence and survival partly because of colinearity. However, the number of LNM was an independent risk factor for recurrence and survival, unless LNR or LNM location was used (data not shown).

Some investigators have recently reported the usefulness of LNR for predicting the prognosis of patients after curative resection for colorectal cancer [11-16]. The present study demonstrated that LNR is a good predictor of recurrence after curative resection for right colon cancer. Adding the concept of LNR and location of LNM to conventional TNM staging could improve the accuracy of evaluating nodal status. Patients at high risk for recurrence with $\mathrm{n} 3 \mathrm{LNM}$ or LNR $\geq 0.15$ might be suitable candidates for cytotoxic adjuvant chemotherapy such as folinic acid, fluorouracil and oxaliplatin.

In the present study, high LNR led to both a high number of positive nodes and low number of lymph nodes retrieved. Kim et al. [13] reported the same tendency as in our study. In their study, the numbers of lymph nodes examined were as follows: 21 (LNR <0.1),
18 (LNR 0.1-0.2), 16 (LNR 0.2-0.4) and 16 (LNR >0.4). The reason why the patients with many positive nodes had fewer lymph nodes retrieved is unclear. A recent study showed that increasing the number of examined lymph nodes to more than 6 did not detect more positive nodes in patients with T3 colon cancer [27]. Our hypothesis is that the number of lymph nodes differs from one person to another and that individuals who naturally have fewer lymph nodes have a tendency to easily metastasize to lymph nodes. This issue should be clarified in further studies.

This retrospective study has potential limitations. The usefulness of CME with high ligation for advanced right colon cancer should be validated by a randomized controlled study. None of our patients received powerful adjuvant chemotherapy such as folinic acid, fluorouracil and oxaliplatin, or folinic acid, fluorouracil and irinotecan. The effectiveness of such adjuvant chemotherapy after CME with high ligation should also be clarified in further studies.

In conclusion, CME with high ligation of major vessels should be a standard therapy for patients with T3-T4 right colon cancer. Not only the number of LNM but also the distribution of LNM and the LNR should be considered with regard to prognosis after curative resection for right colon cancer.

\section{References}

1 Jemal A, Siegel R, Ward E, Hao Y, Xu J, Thun MJ: Cancer statistics, 2009. CA Cancer J Clin 2009;59:225-249.

2 Kotake K, Honjo S, Sugihara K, Kato T, Kodaira S, Takahashi T, Yasutomi M, Muto T, Koyama Y: Changes in colorectal cancer during a 20-year period: an extended report from the multi-institutional registry of large bowel cancer, Japan. Dis Colon Rectum 2003;46:S32-S43.

3 Kapiteijn E, Putter H, van de Velde CJ: Impact of the introduction and training of total mesorectal excision on recurrence and survival in rectal cancer in The Netherlands. $\mathrm{Br}$ J Surg 2002;89:1142-1149.

4 Martling AL, Holm T, Rutqvist LE, Moran BJ, Heald RJ, Cedemark B: Effect of a surgical training programme on outcome of rectal cancer in the County of Stockholm. Stockholm Colorectal Cancer Study Group, Basingstoke Bowel Cancer Research Project. Lancet 2000;356:93-96. $\checkmark 5$ Wibe A, Moller B, Norstein J, Carlsen E, Wiig JN, Heald RJ, Langmark F, Myrvold $\mathrm{HE}$, Soreide O: A national strategic change in treatment policy for rectal cancer - implementation of total mesorectal excision as routine treatment in Norway. A national audit. Dis Colon Rectum 2002;45:857-866.

6 Hohenberger W, Weber K, Matzel K, Papadopoulos T, Merkel S: Standardized surgery for colonic cancer: complete mesocolic excision and central ligation - technical notes and outcome. Colorectal Dis 2009; 11:354364, discussion 364-365.

7 Kobayashi H, Ueno H, Hashiguchi Y, Mochizuki H: Distribution of lymph node metastasis is a prognostic index in patients with stage III colon cancer. Surgery 2006;139: 516-522.

$\checkmark 8$ Toyota S, Ohta H, Anazawa S: Rationale for extent of lymph node dissection for right colon cancer. Dis Colon Rectum 1995;38:705711.

9 Garcia-Ruiz A, Milsom JW, Ludwig KA, Marchesa P: Right colonic arterial anatomy. Implications for laparoscopic surgery. Dis Colon Rectum 1996;39:906-911.
-10 Yamaguchi S, Kuroyanagi H, Milsom JW, Sim R, Shimada H: Venous anatomy of the right colon: precise structure of the major veins and gastrocolic trunk in 58 cadavers. Dis Colon Rectum 2002;45:1337-1340.

$\checkmark 11$ Berger AC, Sigurdson ER, LeVoyer T, Hanlon A, Mayer RJ, Macdonald JS, Catalano PJ, Haller DG: Colon cancer survival is associated with decreasing ratio of metastatic to examined lymph nodes. J Clin Oncol 2005; 23:8706-8712.

$\checkmark 12$ Chin CC, Wang JY, Yeh CY, Kuo YH, Huang WS, Yeh CH: Metastatic lymph node ratio is a more precise predictor of prognosis than number of lymph node metastases in stage III colon cancer. Int J Colorectal Dis 2009;24: 1297-1302.

$\checkmark 13$ Kim YS, Kim JH, Yoon SM, Choi EK, Ahn SD, Lee SW, Kim JC, Yu CS, Kim HC, Kim TW, Chang HM: Lymph node ratio as a prognostic factor in patients with stage III rectal cancer treated with total mesorectal excision followed by chemoradiotherapy. Int J Radiat Oncol Biol Phys 2009;74:796-802. 
-14 Moug SJ, Saldanha JD, McGregor JR, Balsitis M, Diament RH: Positive lymph node retrieval ratio optimises patient staging in colorectal cancer. Br J Cancer 2009;100: 1530-1533.

15 Peschaud F, Benoist S, Julie C, Beauchet A, Penna C, Rougier P, Nordlinger B: The ratio of metastatic to examined lymph nodes is a powerful independent prognostic factor in rectal cancer. Ann Surg 2008;248:1067-1073.

-16 Rosenberg R, Friederichs J, Schuster T, Gertler R, Maak M, Becker K, Grebner A, Ulm K, Hofler H, Nekarda H, Siewert JR: Prognosis of patients with colorectal cancer is associated with lymph node ratio: a singlecenter analysis of 3,026 patients over a 25year time period. Ann Surg 2008;248:968978.

17 Jamieson JK, Dobson JF: The lymphatics of the colon. Proc R Soc Med 1909;2:149-174.

-18 Enker WE, Laffer UT, Block GE: Enhanced survival of patients with colon and rectal cancer is based upon wide anatomic resection. Ann Surg 1979;190:350-360.
19 Rosi PA, Cahill WJ, Carey J: A ten year study of hemicolectomy in the treatment of carcinoma of the left half of the colon. Surg Gynecol Obstet 1962;114:15-24.

20 Slanetz CA Jr, Grimson R: Effect of high and intermediate ligation on survival and recurrence rates following curative resection of colorectal cancer. Dis Colon Rectum 1997; 40:1205-1218, discussion 1218-1219.

21 Pezim ME, Nicholls RJ: Survival after high or low ligation of the inferior mesenteric artery during curative surgery for rectal cancer. Ann Surg 1984;200:729-733.

22 Rouffet F, Hay JM, Vacher B, Fingerhut A, Elhadad A, Flamant Y, Mathon C, Gainan A: Curative resection for left colonic carcinoma: hemicolectomy vs. segmental colectomy. A prospective, controlled, multicenter trial. French Association for Surgical Research. Dis Colon Rectum 1994;37:651-659.

23 Surtees P, Ritchie JK, Phillips RK: High versus low ligation of the inferior mesenteric artery in rectal cancer. Br J Surg 1990;77:618621.
24 Tagliacozzo S, Tocchi A: Extended mesenteric excision in right hemicolectomy for carcinoma of the colon. Int J Colorectal Dis 1997;12:272-275.

25 Hogan AM, Winter DC: Mesocolic plane surgery: just plain surgery? Colorectal Dis 2009;11:430-431.

26 West NP, Hohenberger W, Weber K, Perrakis A, Finan PJ, Quirke P: Complete mesocolic excision with central vascular ligation produces an oncologically superior specimen compared with standard surgery for carcinoma of the colon. J Clin Oncol 2010;28:272278.

27 Baxter NN, Ricciardi R, Simunovic M, Urbach DR, Virnig BA: An evaluation of the relationship between lymph node number and staging in pT3 colon cancer using population-based data. Dis Colon Rectum 2010;53: 65-70. 